\title{
Effects of distractor familiarity on habituation of neophobia
}

\author{
DAVID R. SHANKS, G. C. PRESTON, and KELLY J. STANHOPE \\ University of Cambridge, Cambridge, England
}

\begin{abstract}
When the first presentation of a neophobic flavor is immediately followed by a distractor flavor, habituation of the neophobic response is typically attenuated. This is manifested by the fact that neophobia is still shown to the target flavor on its second presentation. Three experiments investigated the prediction that this effect will occur only for novel, but not familiar, distractor solutions. Experiments 1 and 2 found that, contrary to this prediction, both novel and familiar distractors can attenuate the habituation of a neophobic response. In Experiment 3, however, when the distractor was made very much more familiar, it lost its ability to interfere with the habituation of neophobia to the target solution. These results are discussed in terms of Wagner's (1981) theory of habituation.
\end{abstract}

If a stimulus is repeatedly presented to an animal, then any unconditioned response it originally elicits will tend to decrease. This is called habituation and such habituation obviously depends on the animal's ability to recognize the stimulus as being the same one it has already encountered. When the stimulus is a novel flavor, animals will typically consume only small amounts to begin with ("neophobia"). Neophobia is the unconditioned response to novel flavors. Habituation of neophobia is reflected by increased consumption with repeated presentation of the flavor, and this habituation must depend on recognition of the flavor as the same as that previously presented.

Habituation of neophobia to a target flavor can be dramatically affected if it is immediately followed by a second flavor, which is called a "distractor" (Green \& Parker, 1975; Robertson \& Garrud, 1983). For example, Robertson and Garrud presented animals in a control group with a solution of sucrose for $10 \mathrm{~min}$ and measured their recognition of it by presenting it again $6 \mathrm{~h}$ later. Habituation of neophobia was demonstrated by the observation that the animals drank more of the sucrose on the second presentation than on the first. However, for another group of animals, the first presentation was followed immediately by consumption of a coffee solution; these animals drank less of the sucrose on the second presentation than had animals in the control group. In other words, the coffee had interfered with processing of the sucrose such that recognition of it was impaired.

What is the basis of this distractor effect? Robertson and Garrud attempted to account for it in terms of Wagner's (1976) model of habituation. Wagner assumes that entry of the distractor into short-term memory (STM)

This research was supported by grants from the UK MRC and SERC. We thank Deborah Charnock, Anthony Dickinson, Nick Mackintosh, John Pearce, Mark Price, and Fred Westbrook for their many helpful comments. Requests for reprints should be sent to: David R. Shanks, MRC Applied Psychology Unit, 15 Chaucer Road, Cambridge CB2 2EF, England. displaces the target from STM and so prevents processing of the target stimulus that would otherwise have occurred. Without this processing, habituation of the target stimulus is prevented. The main feature of the distractor is that it is unexpected (Wagner, Rudy, \& Whitlow, 1973). Wagner's model, then, is a simple account of Robertson and Garrud's (1983) and Green and Parker's (1975) distractor effects.

Recently, an updated version of this theory has been presented (Wagner, 1981), which is known as the SOP model, and it is this model that will be considered henceforth. Wagner's (1981) model distinguishes between a limited-capacity STM and a long-term memory (LTM) store, and in addition distinguishes within STM between two activation states, $A 1$ and $A 2$. State $A 1$ is roughly equivalent to the state of "rehearsal," whereas State A2 involves representations that are active in STM but are not undergoing rehearsal (Atkinson \& Shiffrin, 1968; Wagner, 1978). If two events are simultaneously represented in A1, they become associated, whereas an inhibitory association will be formed between an event in $\mathrm{Al}$ and another event represented in $\mathrm{A} 2$ at the same time. Wagner proposes that an event that is represented in A2 will be denied entry into $\mathrm{Al}$.

Wagner's SOP model can account for habituation by saying that an association is formed between the context in which the episode occurs and the habituating stimulus. This association then primes or activates the representation of the stimulus into $\mathrm{A} 2$ and thus prevents the stimulus from gaining entry into $A 1$, as a result of which it elicits a diminished unconditioned response (UR). The unconditioned response in a flavor-consumption procedure is neophobia. The model can also readily account for the distractor effect found by Green and Parker (1975) and Robertson and Garrud (1983). The distractor's entry into the A1 state will displace the target stimulus because of the limited capacity of STM. The target stimulus will therefore not become associated with the context, will not 
be primed into $\mathrm{A} 2$ by the context, will not be subsequently prevented from entering $A 1$ on its second presentation, and so will elicit a UR.

An additional feature of Wagner's theory is that it specifies the nature of those stimuli which should be able to enter into short-term memory and so prevent the processing of the target stimulus. In particular, the theory predicts that only novel, unexpected stimuli should be able to do this; familiar, expected distractors should not, because they will be primed into A2. The theory therefore predicts that neophobia to a target solution should be attenuated only when it is followed by a novel distractor but not by a familiar one. The following experiments attempted to test this claim.

In fact, evidence which seems to support this prediction has already been reported. Best, Gemberling, and Johnson (1979, Experiment 2) found that preexposing a flavor which was subsequently paired with lithium chloride produced latent inhibition of that flavor, that is, a reduction in its rate of conditioning. However, if the preexposure was followed by a novel, but not a familiar, distractor, then the latent inhibition effect was reduced. This effect is exactly what Wagner's theory would predict: the novel, but not the familiar, flavor was capable of displacing the target flavor from the A1 state, and thus was able to reduce processing of the target that would otherwise have resulted in latent inhibition.

\section{EXPERIMENT 1}

In the first experiment, animals consumed vinegar and were then immediately given a second, distractor, solution. Four hours later they were given vinegar again, and the amount they consumed was measured. For some of the animals, the distractor solution was water. These animals should exhibit habituation, or a loss of neophobia, and so they should drink a substantial amount of vinegar on the test. For another group, the second, distractor, solution was a novel one. If this solution interfered with the processing of the vinegar, then these animals should drink less of the vinegar on the test since they would fail to recognize it as the preexposed solution. Animals in a final group were given a familiar solution after the vinegar. According to Wagner's theory, these animals should drink as much vinegar on the second exposure as animals in the control group.

\section{Method}

Subjects and Apparatus. The subjects were 27 male Hooded Lister rats, housed in pairs in wire cages with free access to food but given water for only $30 \mathrm{~min}$ each day. The water was given approximately $2 \mathrm{~h}$ after each day's experimental session. The daily sessions took place in four wire cages measuring $24 \times 19 \times 40 \mathrm{~cm}$. Glass measuring tubes, graduated to $0.1 \mathrm{ml}$, could be inserted through the wire at the front of each cage.

Procedure. On Day 1, the animals were given 10 min access to water in the testing cages; since each animal drank a considerable amount, no further water days were given. On Days 2 and 3, they were given $5 \mathrm{~min}$ preexposure to either a $0.6 \% \mathrm{w} / \mathrm{v}$ solution of salt
(13 animals) or a $12 \% \mathrm{w} / \mathrm{v}$ solution of sucrose (14 animals). The use of salt or sucrose as the distractor was counterbalanced across the groups: thus, in each group, some of the animals had been preexposed to salt and some to sucrose. Day 4 was the neophobia day. The animals were given $5 \mathrm{~min}$ of a $3 \% \mathrm{v} / \mathrm{v}$ vinegar solution followed, in Group Familiar $(n=9)$ by 5 min of the preexposed solution, in Group Novel $(n=9)$ by the nonpreexposed solution, and in Group Control $(n=9)$ by water. Four hours later, the animals were returned to the testing cages and their consumption of vinegar was measured over $15 \mathrm{~min}$.

\section{Results and Discussion}

The data were analyzed by means of post hoc orthogonal contrasts using the procedure of Rodger (1975). This procedure ensures that the per-comparison error rate is equal to $\alpha$. One contrast compared Groups Familiar and Novel, and the other compared Group Control with the mean of Groups Familiar and Novel. With the significance level set at $\alpha=0.05$ and 2,24 degrees of freedom, this yields a critical $F$ ratio of 5.38 .

The mean amount of vinegar drunk on the neophobia trial (the first presentation of the vinegar) was $1.1 \mathrm{ml}$ for Group Novel, $1.1 \mathrm{ml}$ for Group Familiar, and $1.3 \mathrm{ml}$ for Group Control. There were no significant differences between these amounts $(F<1$ for each contrast).

The mean amount of distractor drunk by Group Novel was $6.4 \mathrm{ml}$; the mean amount drunk by Group Familiar was $10.3 \mathrm{ml}$. This difference was significant $(F=9.03)$, implying that the distractor was, indeed, more familiar in Group Familiar. Animals in Group Control drank a mean of $8.7 \mathrm{ml}$ of water.

Table 1 shows the amount of vinegar consumed by each group on the test trial. Group Novel consumed substantially less than Group Control, implying that the consumption of a novel solution immediately after the target solution prevented the loss of neophobia to the target that would otherwise have been found. Of principal interest, however, is that Groups Novel and Familiar did not differ, indicating that the familiarity of the distractor did not affect its ability to interfere with the target solution. These conclusions were confirmed by the statistical analysis, which found that the mean of Group Control was greater than the combined means of Groups Novel and Familiar $(F=10.18)$, and that Groups Novel and Familiar did not differ $(F=1.43)$. An analysis based on the difference between consumption on the test trial and that on the first vinegar presentation revealed precisely the same pattern of results $(F \mathrm{~s}=12.11$ and 1.88 , respectively).

These results imply that novel and familiar distractors interfere equally with the recognition of the target stimulus in a situation where there is independent evidence that the animals can discriminate the distractors on the basis of their familiarity or novelty.

\section{EXPERIMENT 2}

The conclusion to be drawn from the first experiment is that recognition of the target solution is equally impaired when the distractor is novel or familiar. But, although 
Table 1

Design and Results of Experiments 1, 2, and 3

\begin{tabular}{|c|c|c|c|c|}
\hline \multirow[b]{2}{*}{ Group } & \multicolumn{3}{|c|}{ Stimulus } & \multirow{2}{*}{$\begin{array}{c}\text { Mean Test } \\
\text { Consumption }(\mathrm{ml})\end{array}$} \\
\hline & Target Flavor & Distractor & Test & \\
\hline \multicolumn{5}{|c|}{ Experiment 1} \\
\hline Control & vinegar & water & vinegar & 6.0 \\
\hline Novel & vinegar & novel salt/sucrose & vinegar & 2.8 \\
\hline Familiar & vinegar & familiar salt/sucrose & vinegar & 3.9 \\
\hline \multicolumn{5}{|c|}{ Experiment 2} \\
\hline Control & vinegar & water & vinegar & 6.6 \\
\hline Novel & vinegar & novel sait/sucrose & vinegar & 4.9 \\
\hline Familiar & vinegar & familiar salt/sucrose & vinegar & 4.5 \\
\hline \multicolumn{5}{|c|}{ Experiment 3} \\
\hline Control & vinegar & water & vinegar & 1.3 \\
\hline Novel & vinegar & novel salt/sucrose & vinegar & 0.2 \\
\hline Familiar & vinegar & familiar salt/sucrose & vinegar & 1.1 \\
\hline
\end{tabular}

recognition of the target stimulus is equally affected $4 \mathrm{~h}$ later at the time of the test by a novel and a familiar distractor, it is nevertheless possible that a difference would emerge with a more delayed test. In fact, Westbrook, Bond, and Feyer (1981) found exactly such effects in an odor conditioning preparation: long exposure to the odor both 3 and $28 \mathrm{~h}$ before an odor-illness pairing attenuated conditioning to the odor, but short exposure to the odor attenuated subsequent conditioning only at the 3-h interval. In other words, the test at $28 \mathrm{~h}$ was better able to discriminate the short versus the long preexposure effect than was the test at $3 \mathrm{~h}$.

To test for this possibility, Experiment 2 used the same design as that of Experiment 1 except that the recognition test was given $24 \mathrm{~h}$, rather than $4 \mathrm{~h}$, after the initial exposure to the target solution. In addition, to preclude the possibility that differences in consumption might be contributing to the outcome, an attempt was made to match consumption of the distractor in Groups Novel and Familiar.

\section{Method}

Subjects and Apparatus. The subjects were 24 male Hooded Lister rats, maintained as in Experiment 1. Testing occurred in the same apparatus as in the previous experiment.

Procedure. The procedure on Days 1,2, and 3 was identical to that of the previous experiment. On Day 4, the animals were divided into three groups $(n=8)$. The consumption of distractor in Group Familiar was yoked to that of Group Novel by preventing animals in Group Familiar from drinking once they had consumed as much as the corresponding animals in Group Novel. Otherwise, the three groups were treated exactly as the equivalent groups in Experiment 1 for the distractor trial. Day $\mathbf{5}$ was the test day. Consumption of vinegar was measured over $15 \mathrm{~min}$, and this test took place $24 \mathrm{~h}$ after the distractor trial.

\section{Results and Discussion}

Statistical analysis was the same as that used in Experiment 1 . The critical $F$ ratio, with 2,21 degrees of freedom, is 5.48. On the neophobia day (Day 4), animals in Group Novel drank a mean of $1.8 \mathrm{ml}$ of vinegar solution, Group Familiar consumed $1.2 \mathrm{ml}$, and Group Control drank $1.7 \mathrm{ml}$. These amounts did not differ significantly
$(F \mathrm{~s}<1.55)$. Group Novel consumed $9.5 \mathrm{ml}$ of the distractor, and Group Familiar drank $10.6 \mathrm{ml}$; Group Control drank $7.7 \mathrm{ml}$ of water. The difference between consumption of distractor in Groups Novel and Familiar was not significant $(F=1.49)$, indicating that our yoking procedure had been relatively successful, although, because of the difficulty in exact yoking of consumption with our apparatus, the means are not identical.

Table 1 shows the mean amount of vinegar solution consumed by each group on the test trial. Less was drunk by animals in Group Novel than by those in Group Control, indicating that the novel distractor enhanced neophobia to the target solution. But, again, consumption was similar in Groups Novel and Familiar, implying that the familiarity of the distractor did not affect its ability to interfere with the target vinegar solution. The analysis confirmed that there was no significant difference between consumption in Groups Novel and Familiar $(F<1)$. Because of variability within the groups, the comparison between Group Control and Groups Novel and Familiar combined just failed to reach significance $(F=5.02)$. In order to remove sources of between-subject variation, a second analysis based on the difference between vinegar consumption on the test day and that consumed on the neophobia day was performed. The difference between Group Control and Groups Novel and Familiar combined now reached significance $(F=8.13)$, but there was again no difference between Groups Novel and Familiar $(F<1)$.

The conclusion to be drawn from these results is that recognition of the target solution is unaffected at the time of the test ( $24 \mathrm{~h}$ in Experiment 2 ) by whether the distractor is novel or familiar: both affect recognition of the target equally. And this is just the result obtained when the recognition test occurred $4 \mathrm{~h}$ after the initial exposure to the target.

\section{EXPERIMENT 3}

The results of the previous two experments show, in contradiction to Wagner's (1981) SOP model, that both novel and familiar distractors can equally interfere with the processing of a target solution and prevent its habitu- 
ation. Although Experiment 1 showed that the familiar solution was significantly more familiar than the novel solution, as shown by the amounts of these solutions consumed, it is nevertheless possible that a very much more familiar solution than those used in the first two experiments would not be able to act as a distractor. Experiment 3 therefore used, as the familiar solution, a flavor which had been preexposed eight times instead of the two times used in the first two experiments.

\section{Method}

Subjects and Apparatus. The subjects were 24 male Hooded Lister rats, maintained as in the previous experiments. The testing apparatus and solutions were the same as in the previous experiments.

Procedure. On Days 1-3, the animals were given $10 \mathrm{~min}$ access to water in the testing cages. On Days 4-11, half the animals were given $5 \mathrm{~min}$ preexposure to salt, the other half, $5 \mathrm{~min}$ preexposure to sucrose. Day 12 was the neophobia day. The animals were given $5 \mathrm{~min}$ of vinegar followed, in Group Familiar $(n=8)$, by $5 \mathrm{~min}$ of the preexposed solution, in Group Novel $(n=8)$ by the nonpreexposed solution, and in Group Control $(n=8)$ by water. Four hours later, the animals were returned to the testing cages and their consumption of vinegar was measured over $15 \mathrm{~min}$.

\section{Results and Discussion}

The data were analyzed by means of post hoc orthogonal contrasts using the procedure of Rodger (1975). The first contrast compared Group Familiar with Group Control, and the second compared Group Novel with Groups Control and Familiar combined. With the significance level set at $\alpha=0.05$ and 2,21 degrees of freedom, this yields a critical $F$ ratio of 5.48 .

On the first preexposure day, the animals drank a mean of $4.9 \mathrm{ml}$ of the solution (salt and sucrose combined). By the 8th preexposure day, this amount had risen to $8.3 \mathrm{ml}$. The mean amount of vinegar drunk on the neophobia trial was $0.35 \mathrm{ml}$ for Group Novel, $0.44 \mathrm{ml}$ for Group Familiar, and $0.39 \mathrm{ml}$ for Group Control. Although these amounts are lower than in the previous experiments, there were no significant differences between the amounts $(F<1$ for each contrast).

The mean amount of distractor drunk was $7.4 \mathrm{ml}$ by Group Novel and $7.6 \mathrm{ml}$ by Group Familiar; Group Control drank a mean of $7.5 \mathrm{ml}$ of water, indicating that successful yoking had been achieved.

Table 1 shows the mean amount of vinegar consumed by each group on the test trial. Group Novel consumed substantially less than Group Control, implying that the consumption of a novel solution immediately after the target solution prevented the loss of neophobia to the target that would otherwise have occurred. Of principal interest, however, is that Groups Familiar and Control did not differ, illustrating that a sufficiently familiar distractor does not interfere with habituation. These conclusions were confirmed by the statistical analysis, which found that the mean of Group Novel was less than those of Groups Familiar and Control combined $(F=21.35)$ and that Groups Control and Familiar did not differ $(F<1)$. This pattern of results, then, is consistent with Wagner's SOP model.

\section{GENERAL DISCUSSION}

These experiments have attempted to test Wagner's (1981) SOP model in relation to its account of why a distractor attenuates habituation to a target stimulus. According to this model, a novel, but not a familiar, distractor is capable of entering the A1 state in short-term memory and of displacing the target stimulus from STM, with the result that habituation to the target is impaired. If this account is correct, then recognition of the target as assessed by a neophobia test should be impaired when the distractor is novel but not when it is familiar. But recognition of the target was equally impaired after $4 \mathrm{~h}$ (Experiment 1) and after $24 \mathrm{~h}$ (Experiment 2), as measured by a neophobia test: in both of these experiments, novel and familiar distractors interfered equally with the loss of neophobia that would otherwise have occurred.

Experiments 1 and 2 imply that interfering with the loss of neophobia to a stimulus, by presenting a distractor immediately after it (Green \& Parker, 1975; Robertson \& Garrud, 1983), involves a perceptual process that is not dependent on the animal's prior experience with that distractor. To our knowledge, this is the first demonstration that the novelty of a distractor does not affect its ability to interfere with the loss of neophobia to the target stimulus that would otherwise occur; furthermore, this result was consistent in both experiments. Moreover, in Experiment 1 there is independent evidence that the familiar distractor was indeed more familiar, since the animals drank significantly more of it than of the novel distractor.

In Experiment 3, however, the pattern of results predicted by Wagner was finally found, as a result of making the distractor much more familiar, and therefore the results partially support the SOP model of habituation. In fact, the result of Experiment 3 is consistent with what Best et al. (1979, Experiment 2) found in a latent inhibition procedure. In their experiment they showed that a novel, but not a familiar, distractor was able to prevent the latent inhibition resulting from a preexposure of the target stimulus if that stimulus was immediately followed by the distractor. In order to familiarize the target flavor, which was vanilla solution, they presented it 14 times prior to the distractor episode.

But how are we to account for the disparate results of the experiments reported here? Two possibilities present themselves. Perhaps the most obvious is that it is only when a stimulus is strongly familiar that it will not be processed in short-term memory. In other words, in the first experiment, it could have been that although the familiar distractor was sufficiently familiar for the animals to drink more of it than of the novel distractor, it was still not familiar enough not to enter, at least partially, 
the A1 state in short-term memory and thus displace the target solution.

An alternative explanation is that the sensory and affective properties of the distractor are independent. In fact, the view that the encoding of a stimulus might have separate sensory (or perceptual) and affective (or emotional) components is a common one (e.g., Konorski, 1967). To be more specific, suppose that the affective properties of a stimulus are acquired more readily than the sensory ones. In Experiment 1, for example, the amount of preexposure to the familiar distractor may have been sufficient for its affective properties to be learned (more of it was consumed than of the novel distractor), but the preexposure may not have been sufficient for a detailed sensory discrimination to be made between the familiar and novel distractor. If distraction depends on the sensory properties of the stimulus, then at this level of familiarity, no difference between the novel and familiar solutions would be found.

The level of familiarity in the third experiment, however, may have been sufficient for an adequate sensory as well as affective representation of the familiar solution to be formed. If this representation of the sensory properties were sufficient to discriminate the novel and familiar solutions, then a difference in the amount of distraction would occur. Distinguishing these possibilities may well clarify the nature of the mechanisms underlying habituation.

\section{REFERENCES}

Atkinson, R. C., \& Shiffrin, R. M. (1968). Human memory: A proposed system and its control processes. In K. W. Spence (Ed.), The psychology of learning and motivation (Vol. 2). New York: Academic Press.

Best, M. R., Gemberling, G. A., \& Johnson, P. E. (1979). Disrupting the conditioned stimulus preexposure effect in flavor-aversion learning: Effects of interoceptive distractor manipulations. Journal of $E x-$ perimental Psychology: Animal Behavior Processes, 5, 321-334.

GREEN, K. F., \& PARKER, L. A. (1975). Gustatory memory: Incubation and interference. Behavioral Biology, 13, 359-367.

KoNORSKI, J. (1967). Integrative activity of the brain. Chicago: University of Chicago Press.

ROBERTSON, D., \& GARRUD, P. (1983). Variable processing of flavors in rat STM. Animal Learning \& Behavior, 11, 474-482.

RODGER, R. S. (1975). The number of non-zero, post-hoc contrasts from ANOVA and error-rate I. British Journal of Mathematical \& Statistical Psychology, 28, 71-78.

W AGNer, A. R. (1976). Priming in STM: An information processing mechanism for self-generated or retrieval-generated depression in performance. In T. J. Tighe \& R. N. Leaton (Eds.), Habituation: Perspectives from child development, animal behavior, and neurophysiology. Hillsdale, NJ: Erlbaum.

WAGNER, A. R. (1978). Expectancies and the priming of STM. In S. H. Hulse, H. Fowler, \& W. K. Honig (Eds.), Cognitive processes in animal behavior. Hillsdale, $\mathrm{NJ}$ : Erlbaum.

WAGNER, A. R. (1981). SOP; A model of automatic memory processing in animal behavior. In N. E. Spear \& R. R. Miller (Eds.), Information processing in animals: Memory mechanisms. Hillsdale, $\mathrm{NJ}$ : Erlbaum.

WAGner, A. R., Rudy, J. W., Whitlow, J. W. (1973). Rehearsal in animal conditioning. Journal of Experimental Psychology Monograph, 97, 407-426.

WeStBrook, R. F., Bond, N. W., \& FeYer, A.-M. (1981). Short- and long-term decrements in toxicosis-induced odor-aversion learning: The role of duration of exposure to an odor. Joumal of Experimental Psychology: Animal Behavior Processes, 7, 362-381.

(Manuscript received March 8, 1985; revision accepted for publication June 2,1986 .) 